BRUNA FETTER

[I]

A $30^{a}$ Bienal de São Paulo:

entrevistas com Luis Pérez-

Oramas e André Severo 


\section{A 30ª BIENAL DE SÃO PAULO: ENTREVISTAS COM LUIS PÉREZ-ORAMAS E ANDRÉ SEVERO}

A 30ª Bienal Internacional de São Paulo, cognominada A Iminência das Poéticas, de 7 de setembro a 9 de dezembro de 20I2, no Pavilhão da Bienal, Parque do Ibirapuera, é uma realização conduzida pelo curador Luis Pérez-Oramas e pelos curadores associados André Severo e Tobi Maier, tendo Isabela Villanueva como curadora assistente. Em 4 e II de outubro foram realizadas conversas com Pérez-Oramas e com Severo, respectivamente.

\section{Entrevista com Luis Pérez-Oramas, curador da 30ªnal Internacional de São Paulo}

\section{Bruna Fetter:}

Gostaria que você começasse falando sobre o conceito geral que norteia a $30^{\mathrm{a}}$ Bienal de São Paulo e que se apresenta sob o título $A$ iminência das poéticas.

\section{Luis Pérez-Oramas:}

$\mathrm{Na}$ realidade, quando começamos a pensar a Bienal - intuitivamente, sabíamos, mas depois ficou claro, explicitamente claro -, nós queríamos escapar do modelo de uma bienal que se anuncia no título. Anuncia-se no sentido de uma bienal que tem um tema e que a audiência pode esperar uma seleção de artistas vinculados ilustrativamente ou representacionalmente com esse tema. É por isso que nós achamos um motivo - eu gosto de falar de um motivo, mais do que de um tema -, um motivo que foi resumido neste título, já sabendo também que a bienal seria conhecida como a trigésima. $E$ gostávamos de um motivo, quase no sentido de motivo musical, que fosse pretexto para desdobramentos que transcenderiam a ideia de uma bienal contida pelo seu título, que conteria a bienal. Obviamente eu tinha uma intuição sobre a necessidade - que foi notavelmente compartilhada com André Severo -, sobre uma bienal que colocaria no centro de sua discussão a questão da sobrevivência das formas, no sentido de Aby Warburg, do Nachleben, que significa a vida e depois a vida das formas. Que para mim é fundamental entender, contra o mito do progresso moderno e contra 
o mito do ineditismo das formas modernas, que as ressurgências constituem as emergências, que as ressurgências nas formas constituem as emergências das formas. Este fato, obviamente, implicava necessariamente pensar uma noção de retorno. Mas pensar a noção de retorno no mundo da arte contemporânea é uma armadilha. A única maneira que a arte contemporânea tem para pensar a questão do retorno é o retorno à ordem, ou o retorno ao passado ou o retorno ciente, e não é este o retorno que nós estávamos interessados em colocar no centro da discussão. Era mais o fato de que as formas são sempre deformações de outras formas, o fato de que a emergência da memória - que é uma emergência que está além de todo o programa, além de todo o projeto, além de toda a intenção -, esta emergência, é constitutiva da possibilidade das formas. Obviamente nós sabíamos que há práticas artísticas radicais, como as práticas de deriva, que escapam à lógica de uma forma que se constitui como terminada, e que há práticas artísticas contemporâneas que revisitam a cena moderna e que são, de fato, ressurgências ou sobrevivências ou alterformas das formas modernas. Tudo isso estava na nossa consciência, mas para nós o importante era entender que o que nós queríamos colocar no centro da discussão não tinha um nome. E um dia, numa discussão com Homi Bhabha, apareceu a noção de iminência, e ficou claro que essa noção de iminência podia ser, precisamente, um nome para essa questão que nós estávamos intuindo. Hoje eu entendo que a questão da iminência tem um desdobramento, ao menos, duplo. É uma maneira oportuna de voltar a colocar o problema do tempo iminencial que está presente em todas as discussões do mundo contemporâneo, um mundo que só existe em temporalidade iminencial e que permanentemente resiste à possibilidade de ser integralmente pensado, revisto e etc. pelos grandes sistemas. Mas a outra dimensão da iminência que hoje para mim é mais clara, na intuição que nós tínhamos, era essa que foi esclarecida para nós pelo Homi Bhabha e que está claramente exposta por ele no texto do catálogo. É que as formas artísticas só existem em tempo iminencial, que elas acontecem cada vez novamente e que elas existem na interação e na diferença com elas mesmas neste acontecimento. A segunda coisa, que eu tinha claro para construir com meus co-curadores esse motivo - motivo que não é um tema, motivo que não é um título -, era a questão das poéticas, e de uma questão mais crítica em relação ao mundo contemporâneo. Eu conto isso um pouco no meu texto. Acho importante entender que as práticas artísticas contemporâneas são cada vez mais em um modo discursivo, mas que o mundo da arte contemporânea as trata como se fossem práticas pré-discursivas ou metadiscursivas, que o mundo da arte contemporânea trata as formas artísticas contemporâneas como se elas fossem ainda modernas, como se elas fossem outra coisa diferente do que elas são. $E$ que se as artes contemporâneas se opõem à modernidade, no sentido que a modernidade reclamava ou clamava ou reivindicava um estatuto especial de linguagem, um estatuto de linguagem que 
não seria a linguagem da tribo. As práticas artísticas contemporâneas reivindicam formar parte das linguagens da tribo, das linguagens ordinárias. E nesse sentido são arte discursiva. E a pergunta que me coloco, para a qual não tenho resposta, é: se acaso não seria isso uma ressurgência também, de uma questão humanística, que é a relação entre a discursividade reguladora e a potencialidade imaginária na arte? Mas, fundamentalmente, o que eu queria tentar colocar na discussão é o fato de que provavelmente a poética - no sentido antigo -, as poéticas não seriam um arsenal de perguntas de uma arte contemporânea que se pretende uma arte, cada vez mais, discursiva. E daí a multiplicidade das poéticas e da iminência das poéticas.

\section{BF:}

Esta Bienal foi pensada a partir de constelações (são doze: a construção da imagem, a teatralidade, o objeto encontrado, o mundo ficcionalizado, a dimensão sonora da imagem, a serialidade, o olhar antropológico sobre a realidade cotidiana, o inesperado, a linguagem, o âmbito público, o arquivo, o território). Ou seja, de formações livres que seriam disparadoras, seja através de analogias de linguagem, seja por memória afetiva, para outras situações. Tal proposição repassaria ao público a liberdade de construir suas próprias associações e diálogos. Como você vê que o público está lidando com essa proposta?

\section{LPO:}

Eu acho que isso está funcionando. Eu estava falando com o André Severo outro dia sobre isso. A preocupação dele era que os vínculos entre fossem possíveis. $E$ um dia ele me perguntou como eu estava percebendo isso e eu acho que está acontecendo. Primeiro, a questão constelar é mais uma questão relacionada a uma certeza quase elemental, que é a certeza linguística, por assim dizer, e que vem do Saussure, segundo o qual os sistemas de linguagem funcionam diferencialmente. Ou seja, os elementos, as unidades de linguagem não produzem significados por eles mesmos, eles produzem significados na medida em que eles marcam uma diferença com outros. E acho que isso pode ser projetado para as formas simbólicas, se elas produzem significado na medida em que elas marcam diferenças com outras, então elas só produzem significação na potencialidade vincular, na possibilidade de ser vinculantes ou vinculadas. E a unidade dos vínculos, a totalidade dos vínculos - uma das formas da totalidade dos vínculos - é uma constelação. Mas para nós não se trata de propor doze constelações. Essas doze constelações são uma possibilidade. É que de fato temos II I artistas, tínhamos que organizá-los, pois os departamentos de comunicação e de educação precisavam produzir dispositivos didáticos e eles precisavam que nós concretizássemos essas constelações. Então, um pouco contra vontade própria, nós começamos a produzir esses relacionamentos que deram 12 constelações, que são abertas como você fala 
e que de fato nunca foram produzidas no prédio da Bienal, na materialização espacial da Bienal. Eu prefiro falar que a materialização constelar da Bienal tem muitas formas, as constelações estão nos catálogos, no guia, no áudio-guia, a pequena constelação que são os cinco livrinhos, etc., etc. E, além de tudo isso, a organização espacial das obras no prédio que, para nós, era importante funcionar vincularmente.Tínhamos que resolver uma equação, que era muito difícil de resolver, e que é muito difícil de resolver, que é a seguinte: queríamos grupos de obras de alguns artistas, que eventualmente fossem retrospectivos, que eventualmente fossem obras de diversos períodos. Com a ideia de que uma organização constelar de obras de um mesmo artista poderia dar conta mais de um processo do que de um resultado. Por outra parte queríamos que esses grupos de obras fossem suficientemente abertos para poder ser vinculados com outros. E sugerimos justaposições materiais no espaço da Bienal. Mas a minha experiência - e estou vindo de uma fala com educadores e mediadores - é que as pessoas estão produzindo seus vínculos, vínculos que nós não vimos. Agora mesmo, me falaram de um vínculo extraordinário entre a Helen Mirra e a Nydia Negromonte que eu não tinha visto, que existe e que é possível.

\section{BF:}

Esta Bienal também tem outra peculiaridade que é a de oferecer espaços bastante generosos a cada artista, espaços nos quais encontramos uma quantidade de obras que acabam por configurar mostras individuais dentro do universo da Bienal. Como foi o processo de materialização do projeto conceitual, a seleção de artistas e obras, em termos espaciais?

\section{LPO:}

Quanto à materialização, o que fez isso possível foi a extraordinária experiência no prédio de Martin Corullon e de sua equipe de arquitetos e à extraordinária comunicação que se estabeleceu entre a curadoria e a arquitetura. Eles entenderam o projeto às claras, as necessidades do projeto, de abertura e etc., eles trouxeram ideias que eram imediatamente proporcionais ao que nós queríamos. Como, por exemplo, produzir uma museografia que fosse de arte e que combinasse altas e baixas intensidades visuais, muito para ver e nada para ver, que não fechasse o prédio, que deixasse circulação lateral e central aberta e possível, que permitisse muitos lugares de olhares que iam do exterior ao exterior através do prédio e que - no lugar de se impor através de uma força metafórica ou alegórica ou de arquitetura mesma - se produzisse em resposta às demandas das obras. Quase a metade dessa curadoria foi feita pelo Martin Corullon no momento em que ele interpretou os grupos de obras e conseguiu espaços que eram perfeitamente proporcionais para elas. 


\section{BF:}

Esta Bienal também se propõe a realizar uma arqueologia recente da arte contemporânea, trazendo obras de artistas menos reconhecidos no circuito internacional, ou ainda, se propondo a reunir um volume de obras significativo como no caso de August Sander, inédito. A partir disso, tenho duas perguntas: I) sobre a relevância destes artistas, seus pensamentos e obras como base, fundamento conceitual de questões relevantes para a $30^{\mathrm{a}}$ Bienal de São Paulo; e 2) como ficaria o papel de uma bienal de artes neste contexto, uma vez que existiria uma expectativa generalizada no meio de que as bienais exponham as grandes novidades da produção artística contemporânea?

\section{LPO:}

Obviamente o destino, a missão da bienal é essa questão da emergência da arte contemporânea. Mas eu acho importante entender que a emergência precisa ter uma densidade e que essa densidade é histórica e que essa densidade não é um fato, é um desafio a ser produzido por nós. Não é só a história que nos produz, nós produzimos a história. A instância de enunciação da história é nossa situação contemporânea. Ao contrário do mito historicista, que acha que a situação de enunciação da história é um ponto passado, originário, que coincide com uma verdade. Então a ideia de arqueologia para mim é sempre uma arqueologia como uma engenharia reversível, você vai para trás e resgata o que você acha proporcional e potencial para colocar como densidade histórica do presente. É assim que eu funciono curatorialmente e intelectualmente. Eu não estou interessado na emergência pela emergência. E acho que a arte contemporânea que se preocupa só da dimensão de emergência inevitavelmente cai na armadilha e na hipoteca mercadotécnica de se fazer inteiramente dependente de um estilo contemporâneo. Em outras palavras, a arte contemporânea que se enuncia ou que se formaliza só em termos de emergência é na realidade um estilo internacional, e não arte contemporânea. E eu sempre coloco essa pergunta: a arte contemporânea é um estilo internacional? E nesse sentido, é uma forma que exclui outras? E enquanto a trazer para a Bienal artistas que eu achava fundamentais, mas não suficientemente reconhecidos, não se tratava do exercício esquisito de procurar artistas raros. Não. Eu acho fundamental entender que a mitologia mercadotécnica das obras mestras é isso: uma mitologia. E que as obras mestras só são possíveis graças às obras, entre aspas, menores. $\mathrm{O}$ que permite um dinamismo topológico e estilístico, e um dinamismo nos nossos interesses na arte e nas nossas escrituras da história da arte, é precisamente descobrir que artistas menores não são tão menores. Enfim, descobrir a potencialidade que nós ainda não víamos em artistas que não tínhamos descoberto como menores. É difícil para eu verbalizar, mas eu queria uma bienal que não fosse uma bienal dos nomes óbvios que a gente acredita serem os grandes gênios do momento. 
Porque eu não acredito que isso seja verdade, mas também porque eu acho que seja importante colocar outras referências em nossos pensamentos, que nos permitam mudar. Para mim Roberto Obregón é um artista fundamental, lan Hamilton Finlay é um artista fundamental, Bernard Frize, Franz EhrardWalther, como Arthur Bispo do Rosário... Quer dizer, são vários artistas fundamentais. Mas o relacionamento deles com outros é o que me interessava. Mas é fundamentalmente para ser consistente com a ideia de que a arte não funciona como uma topografia de escarpas, com picos e abismos, mas como uma topologia de relações planas. Não são grandes picos e grandes abismos, são relações vinculares que na realidade se parecem um rizoma. $\mathrm{E}$ o último, sobre a ideia de obras que se manifestam como sistemas de imagens, para mim, é muito importante entender, hoje, que as obras de arte, as formas simbólicas, as imagens, funcionam como sistemas diferenciais, que a unicidade irrepetível de uma obra única é um mito. E que temos que entender - assim como entendemos faz muito tempo - que a linguagem é um sistema de diferenças, temos que entender as artes visuais são também um sistema de diferenças. E, portanto, era importante para nós trazer obras que, elas mesmas, se materializam como arquivos, como atlas, como sistemas classificatórios, como coleções de imagens, como repetições, como diferenciações de imagens parecidas, ou seja, como sistemas. E por isso, nessa Bienal, tem muita obra desse caráter, onde se insere August Sander, Robert Filliou, como Horst Ademeit e outros. São sistemas que funcionam na possibilidade que eles têm de produzir diferenças entre eles.

\section{BF:}

Li uma declaração sua de que "o destino da Bienal era achar um lugar que deveria estar entre o mercado, a feira de arte e o museu”. Como você percebe a articulação entre essas instâncias em uma bienal? Gostaria que você comentasse essa declaração.

\section{LPO:}

Eu acho que a Bienal tem que achar a cada dia sua missão. Mas eu acho que nós precisamos de instâncias intermediárias para o pensamento e para a experimentação. Instâncias que escapem da aleatoriedade do mercado e da monumentalidade do museu. Por que a aleatoriedade do mercado é o oposto do pensamento e a monumentalidade do museu é o oposto da experimentação. Experimentação no sentido de experimentação hipotética de relações para produzir sentido entre obras, ruptura das cronologias, tentativas de outras organizações. Eu acho que os museus têm um desafio experimental e que muitos deles não enfrentam, outros sim. Mas eu acho que a bienal é uma dessas instâncias potenciais para o pensamento da arte se produzir entre o mercado e o museu, quer dizer, entre o capricho aleatório do valor econômico que determina o valor simbólico e a monumentalização de um valor 
simbólico que determina o econômico, que seria o museu. E entre esses dois eu acho que a bienal é um desses espaços possíveis, a revista acadêmica é outro, etc. Além desse assunto, eu falava que queria escapar da tentação de dois modelos curatoriais, que um é o modelo do hipermercado e o outro é o modelo do etnógrafo. O curadorhipermercado é aquele que simplesmente está fazendo as compras na avenida das compras e que traz o último grito da moda. E o curador-etnógrafo, que vai para os extremos mais exóticos do mundo, o finis terra, e traz o exemplo absolutamente mais esquisito da diferença exótica para alimentar uma posição no mainstream. E eu queria evitar esses dois modelos. Eu acho que evitar esses dois modelos tem a ver com a busca desse espaço intermediário, com a procura de um espaço intermediário para o pensamento que está entre o modelo aleatório do mercado, que determina um valor econômico e produz um valor simbólico, e o modelo monumental do museu, que estabiliza um valor simbólico e determina um valor econômico.

\section{BF:}

Como você gostaria que esta Bienal fosse recebida pelo público em geral? Qual a sua avaliação parcial disso, agora, um mês após a abertura?

\section{LPO:}

Eu te diria duas coisas. Por um lado, eu não sabia como o público reagiria à Bienal. O público não é um sujeito, o público é uma condensação de multiplicidades contraditórias entre elas mesmas. $O$ público pode ser a audiência geral, pode ser a audiência educativa, pode ser a audiência especializada, podem ser os críticos, os artistas. Então, eu não sabia como a Bienal ia ser recebida, mas eu tinha a esperança de que ela seria bem recebida. Eu tinha a esperança que as pessoas pudessem perceber questões sérias, perceber um exercício transparente e honesto de trabalho curatorial que tentamos fazer, e que fosse estimado por tal, não elogiado, mas estimado nessa dimensão. Era uma esperança. Mas eu não tinha nenhuma certeza de que isso seria possível. E eu também não acredito muito na generosidade do mundo da arte, portanto, não estava esperando muito isso. Um mês depois de abrir a Bienal, eu ainda não acredito no que está acontecendo. Eu até sinto um pouco de vergonha, porque as pessoas estão celebrando muito essa Bienal. Mas quer dizer que deu certo não pelo nosso trabalho, deu certo porque uma série de circunstâncias se articularam no momento oportuno, que não estiveram nunca sob nosso controle. Eu acho que vem de um certo cansaço, de um certo modelo expositivo. Eu acho que trouxemos nomes que as pessoas não conheciam, para um público daqui, e que surpreenderam, inclusive, algumas pessoas do público especializado. Eu acho, fundamentalmente, que nós trabalhamos honestamente, transparentemente, declarando quais eram nossos limites e tentando fazer o melhor. $\mathrm{E}$ eu acho que as equipes da Bienal foram muito 
legais, digo, são excelentes. E eu acho que se deu uma coincidência de circunstâncias que - até agora - a avaliação que eu posso fazer é muito positiva. Mas a percepção das coisas, e eu tenho um pouco de medo, é dependendo de uma temporalidade. Poderia ser que essa Bienal seja percebida hoje, até o dia nove de dezembro, como uma coisa muito boa. E que em dois ou três anos, ela perca significação, poderia ser. E poderia ser que ela ganhe com o tempo. Eu acho, para finalizar, em um tom otimista, mas também em um tom de segurança, eu estou convencido que essa Bienal traz artistas que vão determinar por muitos anos referências nas práticas artísticas de nosso espaço cultural e que, se as pessoas se interessassem pelas obras desses artistas, a ressonância da Bienal vai crescer. Eu estou convencido de que aqui trouxemos artistas que são muito importantes e que tem uma grande potencialidade de entrar em diálogo com os interesses e as práticas artísticas de hoje e de um futuro próximo.

\section{Entrevista com André Severo, curador associado da $30^{\mathrm{a}}$ Bienal Internacional de São Paulo.}

\section{Bruna Fetter:}

Quais você considera as suas principais contribuições para o projeto da $30^{\mathrm{a}}$ Bienal de São Paulo?

\section{André Severo:}

Bem, vamos começar pelo começo então. Quando o Luis me convidou para compor a equipe curatorial, era para ser algo muito mais simples do que o que eu acabei fazendo. Ele tinha me convidado para ser curador-adjunto, onde eu teria uma mostra sobre "derivas", onde eu teria autonomia total para pensar essa questão. Mas aí ele me mandou o texto do projeto, eu respondi com algumas considerações, ele me devolveu, a gente escreveu... e de repente, sem me consultar, ele escreveu para a diretoria e propôs uma outra dinâmica, que não seria a dinâmica que normalmente se usa nessas situações. A gente desmontou essa hierarquia. No início nós tínhamos zonas curatoriais, que serviam de baliza, que nos ajudavam a entender as relações, os vínculos que a gente ia propor. Só que essas zonas não ficaram porque a gente não podia deixar que essa amarração conceitual começasse a direcionar a leitura dos trabalhos. Se tem uma coisa que eu acredito sobre curadoria é que, para fazer um projeto desses, tu tens que fazer duas coisas, que são, primeiramente, amarrar conceitualmente a ideia desse projeto e, ao mesmo tempo, saber apagar essa amarração para que isso não conduza a leitura. Neste sentido, a gente teve duas coisas para vencer que entravam um pouco em choque com o tipo de coisas que o Luis faz e o tipo de coisas que eu tenho para fazer. $O$ Luis aposta muito nos vínculos, nessa leitura curatorial que se evidencia e que estabelece um discurso. Esse era o primeiro 
foco, a primeira ideia de construção da Bienal eram esses vínculos, muito baseada no Giordano Bruno, de que as coisas não significam sozinhas, elas começam a significar a partir das relações que a gente estabelece com elas. Ao mesmo tempo - eu parei de fazer exposição dez anos atrás justamente por essas leituras que impediam que um pensamento de arte tivesse autonomia dentro de uma situação coletiva - eu não ia vir para uma bienal para fazer justamente isso. Então partimos de dois problemas. Um era criar essa amarração conceitual, que foi algo feito em várias etapas: tínhamos as zonas, visitamos os artistas, conhecemos todo mundo. Daqui a pouco isso virou um mapa. Um mapa que era só conceitual, um desenho numa folha. Onde essa ideia de constelações não era nada além de como chamávamos esses mapas que fomos fazendo, pensando nos vínculos, nas relações. Essas constelações não tinham um centro, com um artista importante e outros artistas mais novos ou menos novos gravitando. Não. Vou te dar um exemplo: onde um Allan Kaprow fosse centro de uma constelação que tratasse de gesto, de performance, mas ele poderia estar na periferia de outra constelação que tratasse de linguagem, de autonomia, etc. Então esses mapas tinham uma configuração impossível de ser feita espacialmente em três retângulos - que era o que a gente tinha, os três andares do pavilhão da Bienal. Quais eram nossas duas questões? Uma, deixar evidente esses vínculos que amarram esses artistas, que dão densidade para essa Bienal. E outra, como articular isso permitindo que cada trabalho tenha autonomia, que cada projeto, cada pensamento, cada artista esteja na potência que precisa estar. Aí tinha alguns caminhos que poderíamos ter tomado. E optamos - e isso se reflete nessa grande quantidade de obras desta edição - por ter um corpo de trabalho de cada um desses artistas e por construir uma Bienal em diálogo de fato e não que seja uma retórica sobre esse diálogo. Isso no sentido de que fomos conversar com cada um desses artistas - visitamos efetivamente todos, os que estão mortos visitamos os representantes - e vamos não só olhar para o que essas pessoas têm, mas vamos expor o que nós temos.Vamos deixar que todo mundo saiba quais são as regras desse jogo.Vamos deixar todo mundo ciente que tipo de Bienal é essa, no que ela aposta. Nas entrelinhas de tudo isso tem algumas questões, alguns problemas que nos eram caros. Questões de linguagem, questões de criação de discurso, interrogações no sentido de que necessidade é essa que um artista tem de, ao perceber que a linguagem que ele possui - qualquer uma - não dá conta de certas coisas, precisa criar outras maneiras de dizer, ou entender, ou se relacionar com as coisas. Mas retomando, tínhamos essas duas coisas para articular que eram as relações e a autonomia, que era essa possibilidade que cada artista tinha de estar sozinho. Mas não tínhamos certeza se ia funcionar. Resolvemos apostar que esses vínculos iam se dar no percurso, apostar que uma exposição de artes é diferente de uma peça de teatro, de um filme no cinema, onde tu sentas e tu recebes aquilo. Que tu estás passivo enquanto recebe. Já que esse deslocamento é um dado, vamos apostar 
nele para criar esses vínculos, para deixar que isso aconteça. E vamos propor a cada um dos artistas que ele tenha um espaço, que ele desenhe esse espaço junto com a gente. Por exemplo, a gente excluiu a possibilidade de que o espaço de um artista fosse a periferia de outro artista. Nós não temos trabalhos de passagem, só o que está para fora é o que os artistas daqueles espaços pediram, eram obras ou projetos que estavam se dispondo a essa contaminação. Enfim, a ideia era que, percorrendo a Bienal, tu fosses fazendo as relações. Cada sala dessas é um convite. No momento em que tu entras numa sala e aceitas esse convite, a possibilidade é muito grande de que tu apagues esse discurso conceitual e essas amarrações - e mesmo as vizinhanças - e fiques só com aquele trabalho. Depois tu sais, vê outra coisa e começa de novo a articular. Mas, para nós, era muito importante essa entrada, esse momento de estranhamento, esse momento de suspensão. Por trás desse título bastante retórico, A iminência das poéticas, essa ideia de iminência é isso, o que está suspenso, o que está para acontecer e tu não sabes. E que tu não vais saber se tu não te dispuseres para que isso aconteça. Muito das falas que tenho feito, e do contato com a equipe do educativo, está em preservar essa estranheza, esse espaço onde as coisas não estão imediatamente dadas. Todo mundo tem tanto medo desses discursos, e essa coisa do hermetismo da arte cada vez se solidifica mais, e é tão ridículo isso, porque não faz sentido. Essa estranheza, isso acontece todo dia, na vida, com a gente, com as pessoas, a gente antipatiza ou simpatiza com alguém e isso vai ser determinante para tu quereres saber mais ou simplesmente ir embora e querer te afastar de tal pessoa ou de tal situação. Porque na arte não pode ser assim também, num encontro que está sendo posto para o diálogo? Só que esse diálogo - como qualquer coisa na vida -, ele precisa das duas partes para acontecer, precisa de um interesse mínimo, precisa que algo desperte. $E$ às vezes não desperta. Mas voltando, muita coisa dessa Bienal procurava responder a essas duas coisas, que eram muito caras para o Luis, que eram os vínculos; e que eram muito caras para mim, que é a autonomia, com essa leitura que não se dá de imediato, em poder oferecer esse momento de suspensão.

\section{BF:}

Eu gostaria que você citasse alguns artistas que para você foram fundamentais para amarrar os conceitos presentes na mostra, e que, a partir deles, outros foram emanando, usando aqui a ideia das constelações proposta pela curadoria.

\section{AS:}

Essa pergunta é muito difícil de responder no sentido de que, no momento em que as coisas foram se configurando, nós cuidamos muito para apagar os rastros. $O$ que eu poderia mais facilmente responder é quais figuras eram mais caras ao Luis em determinado momento, e quais figuras eram mais caras a mim. $\mathrm{E}$ que, talvez, partir 
delas - que desde um primeiro momento já se estabeleceram dentro da mostra - foi fundamental, porque respondiam de alguma maneira ao que cada um de nós tinha para fazer lá. Acho que no caso do Luis, Finlay sem dúvida é um ponto importante, Horst Ademeit, é um ponto importante, Fernand Deligny é um ponto importante. Para mim - quase o motivo de eu estar lá -,Tehching Hsieh era um ponto, Kaprow era um ponto. Para partir daí para outras coisas. Por exemplo, o Bispo que esteve aí desde o início para responder questões de linguagem. Porque em algum momento dessa Bienal, coisas que acontecem fora do ambiente da arte, mas que tem potência e podem ser lidas dentro desse contexto, foram um dos fios condutores... com Deligny, o próprio Bispo, como algumas outras coisas que têm uma base num pensamento de arte, mas que a conclusão do processo é quase um abandono disso, quase uma saída disso, aí sim o caso do Kaprow, o caso do Tehching Hsieh. Mas essa é uma Bienal que apostava. Por que resolvemos fazer uma coleção de livrinhos, que são textos de filosofia quase arcaicos? Porque muito das nossas discussões para construir essa Bienal se davam fora disso, elas se davam num campo das ideias, de filosofia, de uma ética de buscar entender a arte como possibilidade de pensamento de fato, não apenas de articular discurso, mas de desarticular um pensamento que de outra maneira poderia estar viciado, que poderia dar sempre no mesmo resultado. Pois a partir do momento em que tu partes de um tipo de ferramenta - mesmo a linguagem -, inevitavelmente não vais ter como fugir do limite dessa ferramenta, dessa linguagem.

\section{BF:}

Você citou o Deligny, o Kaprow, o Tehching Hsieh, que são artistas dos anos 1960, 1970, artistas que possuem um pensamento muito potente, mas que não necessariamente são representantes da arte do momento. E daí pergunto: como foi essa construção de atualizar o pensamento deles e de propor esses vínculos?

\section{AS:}

Para responder isso eu tenho que voltar a essas bases, que eram as zonas curatoriais iniciais que tínhamos, e que apagamos para que nenhum artista estivesse ilustrando algum eixo. No início, uma dessas zonas se chamava "deriva” e era para pensar práticas de deslocamento, não apenas físico, mas metafórico e de pensamento, que pudesse talvez chegar num ponto de negação da arte, dessa deriva realmente acontecer para uma saída, ou coisas que vieram de fora do mundo das artes e por algum desvio acabaram entrando e tem relevância. Essa era uma zona. Tínhamos também uma zona que chamava "sobrevivências" e que buscava pensar em algumas obras, alguns projetos, alguns artistas recentes - recentes no sentido dos anos 1960 para cá, que é o momento que a gente passa a chamar isso de arte contemporânea - e tentar entender o que desse pensamento sobrevive com ressonância nos gestos de artistas 
e se atualiza, e por quê. E também era o momento em que - a meu ver, pelo menos - pela última vez a arte se questionou de fato sobre o que eram essas fronteiras, sobre questões de linguagem mesmo, do que se tinha para fazer. Quando se tem o momento de solidificação dessa possibilidade que, a meu ver, é inacreditavelmente potente e que tu vês nas artes visuais e tu não vês em outras coisas. $\bigcirc$ teatro, por mais que já tenha quebrado todas as linguagens, e a gente tenha teatro pós-dramático hoje, ainda tem uma estrutura que tu reconheces, ele ainda tem o ator, ainda tem o público, ainda tem o texto, num ponto ou noutro ainda tem isso. $O$ cinema, a mesma coisa. A música mesmo quando tu anulas o som, ela ainda está buscando isso nem que seja por contraste. Agora, as artes visuais, as artes plásticas, elas não precisam ser visuais, elas não precisam quase nada, elas estão soltas. Para configurar um trabalho de arte podes juntar pensamento da antropologia, da sociologia... e isso é uma potência muito grande. Mas ao mesmo tempo é uma imensa armadilha, porque ao mesmo tempo em que é potente, te joga num campo de permissividade em que facilmente tu podes aplicar o que a gente tem hoje, que é uma gramática da arte contemporânea, para configurar qualquer coisa. Uma terceira zona se chamava "alteformas" e queríamos nos perguntar o que desse pensamento de base sobrevive deformado, transformado, na prática de artistas. E isso se dá em uma quantidade enorme de artistas nos dias de hoje, de artistas que trabalham exclusivamente a partir de referências da própria arte. Que também pode ser uma armadilha, Ouroboros, a serpente que morde o próprio rabo. Mas precisávamos poder pensar o que é a arte contemporânea, o que é disciplina, o que é antidisciplina dentro disso. E tinha uma outra zona que se chamava "vozes" - mais aberto do que isso impossível -, para dar conta da pluralidade de qualquer coisa, mas que tentávamos expandir para algo não só da fala; a potência que isso tem, mas também quando tu decides não falar, quando tu decides dar para outro falar por ti. Essas eram as questões. Mas voltando, esses artistas dos anos 1960, por que essa escolha? É uma reflexão ainda atual, e hoje uma bienal como a Bienal de São Paulo já não tem mais o papel que teve um tempo atrás, sobretudo numa cidade como São Paulo.Tu não precisas trazer o Van Gogh, o Caravaggio... porque já está lá, as pessoas trazem sozinhas. Então a Bienal não tem mais esse papel, estamos desobrigados disso. E como no nosso caso, tinha acabado de ter uma Bienal que propunha uma articulação entre obras muito diferente da que a gente propôs; a mostra que teve no Pavilhão entre a $29^{\mathrm{a}}$ e a $30^{\mathrm{a}}$ Bienal era uma mostra de grandes estrelas, artistas do mercado; então estávamos desobrigados de todas essas coisas, ou seja, a gente podia se concentrar no pensamento, a gente podia se concentrar nessa reflexão. E o fato de trazermos esses artistas dos anos 1960, um Kaprow, o próprio Sander... eles estão lá porque dão conta de um tipo de reflexão, de um tipo de pensamento, pelas apostas dos trabalhos, eles tocam nessas coisas que são relevantes para a gente agora. E mais do que tudo, também - querendo ou não, 


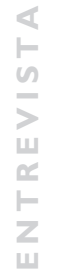

30 Bienal

Internacional de São Paulo, 20 12. Foto:

Porto Arte. mesmo que isso não seja totalmente intencional, mas no fundo eu acho importante marcar -, que tem uma série de coisas que estão sendo feitas hoje, e às vezes quase que por uma apropriação de forma, mas distante do conteúdo, já foram pensadas há mais tempo sem distinção entre forma e conteúdo. Entendo que no nosso trabalho, forma é conteúdo. No momento em que tu estás pensando em discurso, buscando linguagem, tu não tens como dissociar a forma do conteúdo e da maneira como as coisas vão ser apresentadas.
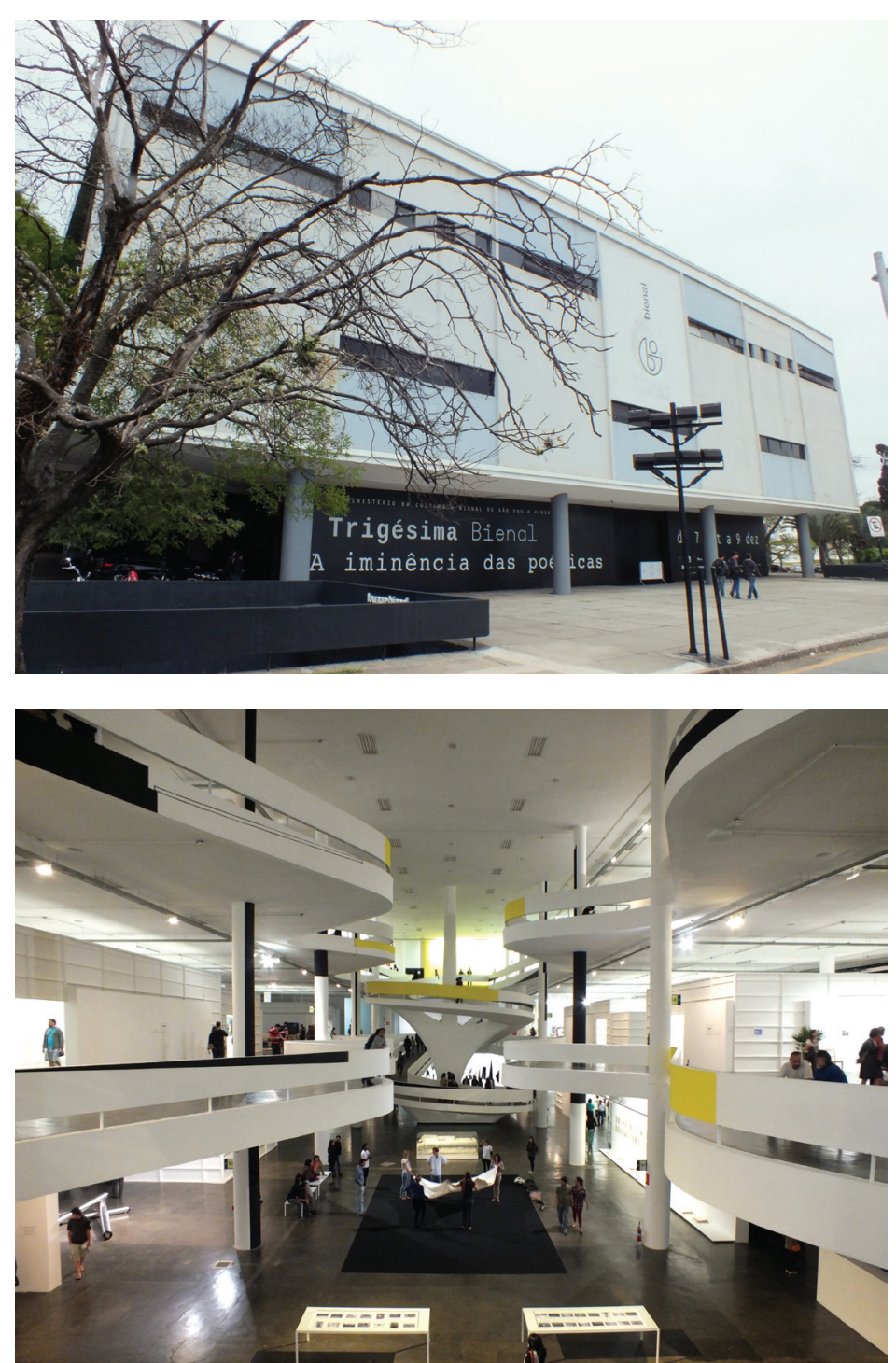


\section{LUIS PÉREZ-ORAMAS}

PhD em História da Arte pela École des Hautes Études en Sciences Sociales, Paris, 1994. Foi professor de história da arte na Université Rennes 2, Haute Bretagne, Rennes, França (1987-1991), na École Régionale Supérieure des Beaux-Arts de Nantes, França (1992-1994), e no Instituto de Estudios Superiores de Artes Plásticas Armando Reverón, Caracas, Venezuela (1995-2002). Foi membro da diretoria da Galería de Arte Nacional (1995-200I) e curador da Colección Patricia Phelps de Cisneros (1995-2002), ambas em Caracas. Em 2003 tornou-se curador adjunto no Department of Drawings do Museum of Modern Art (MoMA), Nova York, e, em dezembro de 2006, foi apontado The Estrellita Brodsky Curator of Latin American Art no MoMA. Curador da $30^{\text {a }}$ Bienal de São Paulo, 2012. Natural de Caracas, Venezuela, vive em Nova York.

\section{ANDRÉ SCHULZ SEVERO}

Graduado e Mestre em Poéticas Visuais pela Universidade Federal do Rio Grande do Sul, UFRGS (2007). Participou da criação ou colaborou com projetos de ação ou documentação da arte contemporânea, como Areal, Lomba Alta e Dois Vazios. participou do Projeto Pedagógico da 7a Bienal do Mercosul, Porto Alegre. Foi um dos curadores da mostra Horizonte Expandido, no Santander Cultural, Porto Alegre, cidade onde vive.

\section{[I]}

\section{BRUNA FETTER}

Doutoranda em História, Teoria e Crítica pelo Programa de Pós-Graduação em Artes Visuais do Instituto de Artes da UFRGS. Mestre em Ciências Sociais pela PUCRS, traz em sua bagagem profissional experiências diversificadas na produção de projetos de artes visuais, como Agora/Ágora e Horizonte Expandido, mostras realizadas no Santander Cultural de Porto Alegre e a coordenação da equipe de produção da $6^{a}$ Bienal do Mercosul. 
